\title{
ОСОБЕННОСТИ ИЗМЕНЕНИЙ ЭЛЕКТРИЧЕСКОЙ АКТИВНОСТИ ЭКСПИРАТОРНЫХ ДЫХАТЕЛЬНЫХ МЫШЦ У БОЛЬНЫХ САХАРНЫМ ДИАБЕТОМ 2 ТИПА
}

\author{
Кунарбаева А.К., Иванов К.М., Сивожелезова О.К.
}

ФГБОУ ВО «Оренбургский государственный медицинский университет» Минздрава России, Оренбург чуз «КБ «РЖД-Медицина» г.Оренбург», Оренбург

ЦЕЛЬ: выявить особенности изменений электрической активности экспираторных дыхательных мышц у больных сахарным диабетом 2 типа.

МАТЕРИАЛЫ И МЕТОДЫ: в исследование были включены 46 мужчин, которые были разделены на 2 группы. Первую группу составили 19 пациентов с сахарным диабетом 2 типа (СД), средний возраст $52,6 \pm 2,0$ лет. В группу сравнения, рандомизированную с основной по возрасту вошли 24 человека без нарушений углеводного обмена. Критерии исключения: заболевания органов дыхания, ХСН ІІБ-ІІІ ст., Выраженное органическое поражение центральной нервной системы, острое нарушение мозгового кровообращения в анамнезе, синдром диабетической стопы V ст. по Wagner, ожирение 3 степени, анемия средней и тяжелой степени, выраженное нарушение функции печени и почек, наличие онкологического заболевания, не синусовый ритм, прием психотропных препаратов и препаратов, замедляющих нервно-мышечную проводимость. Исследование было одобрено локальным этическим комитетом ФГБОУ ВО «ОрГМУ» Минздрава РФ. Определялись антропометрические показатели: рост, масса тела, окружность грудной клетки (ОГК), объем талии (ОТ), объем бедер (ОБ), коэффициент ОТ/ОБ, индекс массы тела (ИМТ). Для оценки электрической активности экспираторных дыхательных мышц проводили биполярную поверхностную электромиографию (ЭМГ) с проведением функциональной нагрузочной пробы 30\% от максимального экспираторного усилия. Статистическая обработка полученных результатов проводилась в программе «Statistica 10.0» с использованием непараметрических методов, корреляционного и дисперсионного анализов.

PЕЗУЛЬТАТЫ: у больных СД значения веса, ИМТ, ОГК, ОТ, ОТ/ОБ были достоверно выше, чем во 2 группе. Масса тела в 1 группе была больше на 9,7\%, ИМТ на 3,7\%, ОГК на 10,0\%, ОТ на 10,5\%, ОТ/ОБ на 5,8\%. При выполнении больными функциональной пробы с повышением нагрузки в обеих группах наблюдалось увеличение показателей амплитуды и уменьшение показателей частоты, однако у больных СД динамика была менее выраженной. Наиболее значительное снижение электрической активности наблюдалось на наружной косой мышце живота (НКМ). В 1 группе амплитуда ЭМГ НКМ увеличилась на 2,2\% от 5 секунды к 10 секунде, от 10 секунды к 15 секунде - на 1,4\% (ps0,05); во 2 группе - на 7,7\% и 10,7\% соответственно (p $\leq 0,05)$. Частота ЭМГ НКМ уменьшалась в 1 группе на 3,2\% от 5 секунды к 10 секунде и на 1,6\%

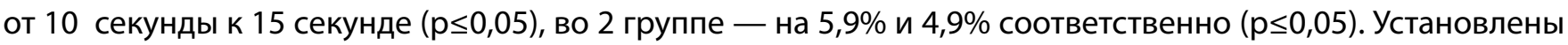
отрицательные корреляционные связи между показателями электрической активности НКМ и массой тела $(r=-0,44, p \leq 0,05)$, ИМТ ( $r=-0,45, p \leq 0,05)$ и ОТ ( $r=-0,40, p \leq 0,05)$. Дисперсионный анализ показал наличие влияния СД на электрическую активность НKM (F=4,6, p $\leq 0,05)$, влияние антропометрических показателей было статистически недостоверным.

\section{ВЫВОДЫ.}

1. Выявлено снижение электрической активности экспираторных дыхательных мышц у больных сахарным диабетом 2 типа.

2. Имеется отрицательная корреляционная зависимость между показателями амплитуды ЭМГ НКМ и антропометрическими данными. 3. Использование функциональной пробы с дозированным экспираторным усилием при проведении ЭМГ позволяет расширить возможности электромиграфического исследования. 